\title{
Wind-driven rain incidence parameters obtained by hygrothermal simulation
}

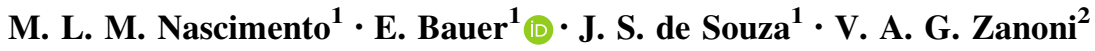

Received: 22 June 2016/Accepted: 16 September 2016/Published online: 29 September 2016

(C) Springer International Publishing Switzerland 2016

\begin{abstract}
The association of rain and wind composes wind-driven rain (WDR), and its incidence may be crucial to the emergence of anomalies on the facades of buildings. Moisture from the WDR can influence the humidification and drying process, therefore the durability and hygrothermal performance are conditioned by the amount of incident water. The quantification of WDR can be an indispensable tool for understanding its related phenomena and the service life of buildings. The most widely used methods of quantification are the semi-empirical, with theoretical basis, but coefficients partially determined from measurements. These methods may take into account the building exposure conditions related to the envelope, solar orientation, height of the building, and other parameters. In this context, in order to contribute to the studies on quantification of WDR, the purpose of this paper is to apply hygrothermal simulation software $\mathrm{WUFI}^{\circledR}$ on quantification of WDR focusing on buildings degradation of BrasíliaBrazil. For the simulation it was used a Typical Meteorological Year file with the wind and precipitation measurement data indispensable for simulation. The quantification of incidence of WDR considered the orientations North, Northeast, East, Southeast, South, Southwest, West, and Northwest. The use of semi-empirical WUFI ${ }^{\circledR}$ quantification method allowed finding the highest values and
\end{abstract}

$\triangle$ E. Bauer

elbauerlem@gmail.com

1 Post-Graduate Program in Structures and Civil Construction, Civil and Environmental Engineering Department, University of Brasília, Campus Universitário Darcy Ribeiro, Asa Norte, 70910-900 Brasília, DF, Brazil

2 Faculty of Architecture and Urbanism, University of Brasília, Campus Universitário Darcy Ribeiro, Asa Norte, 70910-900 Brasília, DF, Brazil consequently critical orientations North, Northwest, and Northeast, moreover, this results showed the relation with the degradation of facades in these orientations. WUFI proved to be an easy, fast and efficient method of WDR quantification, without hiding seasonal weather effects.

Keywords Degradation · Wind-driven rain · Hygrothermal simulation $\cdot$ Facade

\section{Introduction}

Moisture may be the main degradation agent of buildings. Corrosion, cracks, infiltration, efflorescence, leaching, staining, and detachments of coatings are some anomalies related to it. Moisture is from the most diverse possible sources, as Straube [1] highlights: liquid water from precipitation or plumbing leaks, water vapor from exterior and activities/process, liquid and vapor from the soil, but also moisture from construction.

Water incidence in facades can affect the durability and hygrothermal performance of buildings. Presence of moisture in the walls increases thermal conductivity, consequently reducing thermal resistance. Thus, facades are more susceptible to the action of heat. These findings, among others, make the understanding of hygrothermal behavior as a useful task on decision-making process associated to actions in face of exposure conditions of each building, with the goal to decrease problems related to moisture and energy efficiency [2].

Constructive aspects relevant to design and construction of walls as design details, characteristics of components, type of surface finish, etc. affect behavior of porous materials when influenced by moisture. The penetration and transport of moisture in the facade depends on several 
factors acting together, such as: temperature, variation in relative humidity, incidence of solar radiation and precipitation. Furthermore, these factors are also agents that can cause natural degradation of the envelope of buildings [3].

Facades are the first part of the building to receive the incidence of degradation agents. Components of these systems are subject to physical, chemical and biological deterioration who causes the reduction of service life. In this context, the environment around the building influences on the durability of the envelope, predominantly as a result of the action from climate factors.

The association of rain and wind called wind-driven rain (WDR) is a climate factor and can be considered the main source of moisture on the facades of buildings [4]. Both the water deposited on the surface and the portion that penetrates are causes of facades' deterioration mechanisms, and also wind and precipitation influence these aspects, in addition to the characteristics of building envelope [1].

In recent decades, the complexity of WDR phenomena, as well as the emergence of anomalies due to moisture action caused the intensification in studies on quantification of WDR. The understanding of the phenomena related to these aspects improves the knowledge of external factors that influence facades durability. Therefore, the estimation of WDR is a useful tool for design of buildings to avoid premature anomalies of components and systems [5]. These results, can also be used as an auxiliary tool in facades degradation studies or even the definition of maintenance strategies. Other tools in this context are: infrared thermography [6, 7], laboratory experiments on evaluation of water transport, shrinkage and expansion of cementitious materials [8] and smaller building models [9], among others.

Within this context, the purpose of the paper is to apply hygrothermal simulation on quantification of WDR focusing on buildings degradation studies. This is a new perspective of using this tool, which is often used in studies of thermal comfort, energy efficiency, identification of condensation and others [2, 10]. Furthermore, it presents and discusses the WDR semi-empirical quantification method used by hygrothermal simulation software WUFI ${ }^{\circledR}$ Pro 5.3., applied to the case of Brasília-Brazil.

\section{Wind-driven rain}

WDR is the amount of rain that passes through a vertical plane in the atmosphere, and it occurs because of the raindrops path is the result of gravitational forces and wind speed. Furthermore, raindrop size influences the rainfall rate [11].

The study of WDR consists in two different moments: (1) seconds before the raindrop impact on the surface of the envelope (quantification of WDR loads), and (2) on the evaluation of the building system response to this impact [12]. For the former, the main constraints are: urban and building geometry; geometry, detailing and placement of the facade and meteorological variables involved (wind speed and direction, rain intensity and size distribution of raindrops) [4]. When studying the response of the system to WDR, besides knowing parameters that govern the intensity of agents on the facade the properties of materials in relation to transport and moisture storage are important to define.

According to Blocken and Carmeliet [12] the methods used to quantify WDR on a facade are classified into three categories:

- Measurements: field measurements [13-15];

- Semi-empirical: with theoretical basis, but with coefficients partially determined by measurements [16, 17];

- Numerical or computational fluid dynamics methods (CFD): based on fluid dynamics [18].

Measurements are protracted, expensive and often impractical for their peculiarities, therefore, they are less used. CFD models are very complex too, and for this reason its results are not obtained faster than semi-empirical. As presented by Blocken and Carmeliet [12] among the semi-empirical methods, those highlighted are models of ISO 15927-3:2009, Straube and Burnet model, model of ANSI/ASHRAE STANDARD 160:2009, and due to an increase in the use WUFI ${ }^{\circledR}$ model (which is related in this paper) can be considered. When the methodologies are compared each one leads to different amounts of WDR, and it can significantly alter the moisture content in the calculated materials [19]. These data are important for the hygrothermal simulations, since the insertion of values, which do not reflect reality can affect output results. Consequently, it affects the latter moment of study of WDR (evaluation of impact response).

Semi-empirical methods use Eq. 1, as the calculation basis for quantifying WDR in each orientation of facade. In general, the parameter $\alpha$ changes in each model [12].

$\mathrm{I}=\alpha \cdot \mathrm{V} \cdot \mathrm{P} \cdot \cos \theta$

where I is the amount of WDR $\left(1 / \mathrm{h} \mathrm{m}^{2}\right.$ or $\left.\mathrm{mm} / \mathrm{h}\right), \alpha$ is the coefficient of WDR, $\mathrm{V}$ is the wind speed at $10 \mathrm{~m}$ height $(\mathrm{m} / \mathrm{s}), P$ is precipitation $\left(1 / \mathrm{h} \mathrm{m}^{2}\right.$ or $\left.\mathrm{mm} / \mathrm{h}\right)$, and $\theta$ is the angle between the wind direction and the normal to the facade $\left(^{\circ}\right)$.

Generally, parameter $\alpha$ changes in each model of WDR calculation, and its value varies from 0.02 to $0.26 \mathrm{~s} / \mathrm{m}$ [4]. Additionally, with this model is possible, for example, to calculate the values times a day, and monthly or annual sum. The insertion of the wind direction and speed angle for different regions allows specific calculations for each facade of the building. 


\section{Research procedure}

Research procedure consists in two parts, the former presents WUFI ${ }^{\circledR}$ method for quantification of WDR, and the latter shows the definition aspects for the case study.

\section{WUFI $^{\circledR}$ WDR calculation method}

$\mathrm{WUFI}^{\circledR}$ is a hygrothermal simulation software developed in Germany by Fraunhofer Institute for Building Physics (IBP). This tool allows simulation of different construction systems subjected to different climatic variations, which the heat and moisture transport in materials are considered. The software uses an own method for WDR quantification, which is dependent on rainfall, speed and direction of wind. Therefore, is indispensable to dispose of these values in hourly data, so it is possible to proceed with the hygrothermal simulation [19]. For WDR calculation software uses Eq. 2.

$R_{w d r}=R_{h} \cdot\left(R_{1}+R_{2} \cdot V \cdot \cos \theta\right)$

where $R_{w d r}$ is the WDR intensity $(\mathrm{mm} / \mathrm{h}), R_{h}$ is the rainfall in horizontal surface $(\mathrm{mm} / \mathrm{h}), \mathrm{R}_{1}$ is the coefficient dependent on the studied surface inclination, $R_{2}$ is the coefficient dependent on the buildings height $(\mathrm{s} / \mathrm{m}), V$ is the average hourly wind speed at 10 meters height $(\mathrm{m} / \mathrm{s})$, and $\theta$ is the angle between the wind direction and the normal to the facade $\left(^{\circ}\right)$.

Karagiozis et al. [20] using computer simulations based on fluid dynamics determined the $\mathrm{R}_{1}$ and $\mathrm{R}_{2}$ coefficients. For inclinations higher than $90^{\circ}, \mathrm{R}_{1}=1$ and $\mathrm{R}_{2}=0$, while for vertical surfaces (inclination $=90^{\circ}$ ) $R_{1}=0$ and $R_{2}$ depends on the height. The software has a classification for short buildings $(<10 \mathrm{~m})$ and tall buildings (more than $20 \mathrm{~m}$ ), and according to height $R_{2}$ coefficient values are shown in Fig. 1 . It shows an occurrence of a duplication at each height level, and thus the WDR values have the same tendency.

The $R_{2}$ coefficients reflect differentiation of wind flow around the building. It is observed that the higher the building the greater is the amount of precipitation (varying only the $\mathrm{R}_{2}$ coefficient). It occurs because rainfall tends to achieve a greater amount on higher and sides of buildings

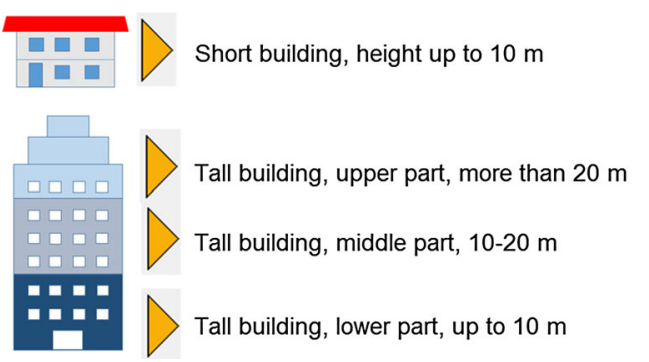

$\mathrm{R}_{2}(\mathrm{~s} / \mathrm{m})$
0,07
0,2
0,1
0,05

Fig. $1 \mathrm{R}_{2}$ coefficient values. Adapted from WUFI ${ }^{\circledR}$ Pro 5.3 [21]
(Fig. 2) regardless of intensity and due to winds movements [22, 23]. In Fig. 3, this same comportment can be seen on the field.

After calculation of WDR values, software considers that only $70 \%$ is available to be absorbed by the facade. The rain water able to penetrate into the facade may be less than half the expected value, and the other half can be lost in trajectory deviations by wind flow and because of constraints [22]. Then, values can be useful for the study related to the system's response in relation to storage and moisture transport, as mentioned in Sect. 2.

\section{Methodology of collection and processing data}

The case study is the city of Brasilia, the capital of Brazil, and it conditions all the definition of information for simulation on WUFI ${ }^{\circledR}$ Pro 5.3. As mentioned on the Sect. 3.1, WUFI $^{\circledR}$ method requires hourly data for rainfall and wind. So, it was used the Typical Metereological Year (TMY) weather file developed by Roriz [24]. This file has 8760 climatic data related to a typical year, and it was drawn from 10 years of measurements of INMET (National Institute of Meteorology of Brazil). The same platform presents files for 411 Brazilian cities, moreover, the software has a large number of TMY files in its database: 85 cities in Europe, 64 in North America, 14 in Oceania, 7 in Japan and 2 in South America.

Then, definition of other aspects of the simulation is required, such as the facade's cardinal or intermediate orientations, surface inclination, and height of the studied

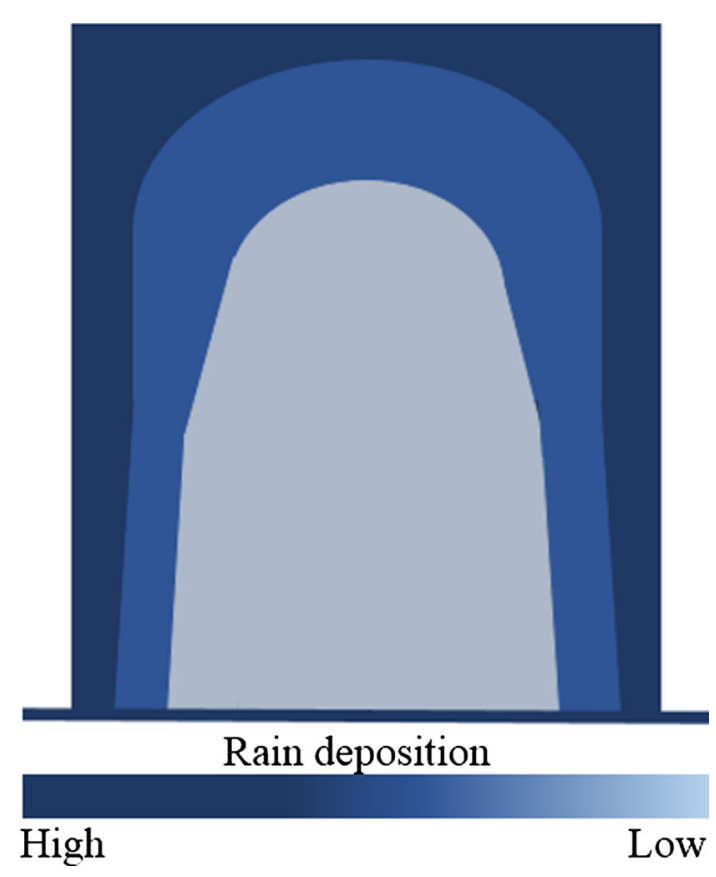

Fig. 2 Wetting geometry of facade, adapted from Straube [22] 


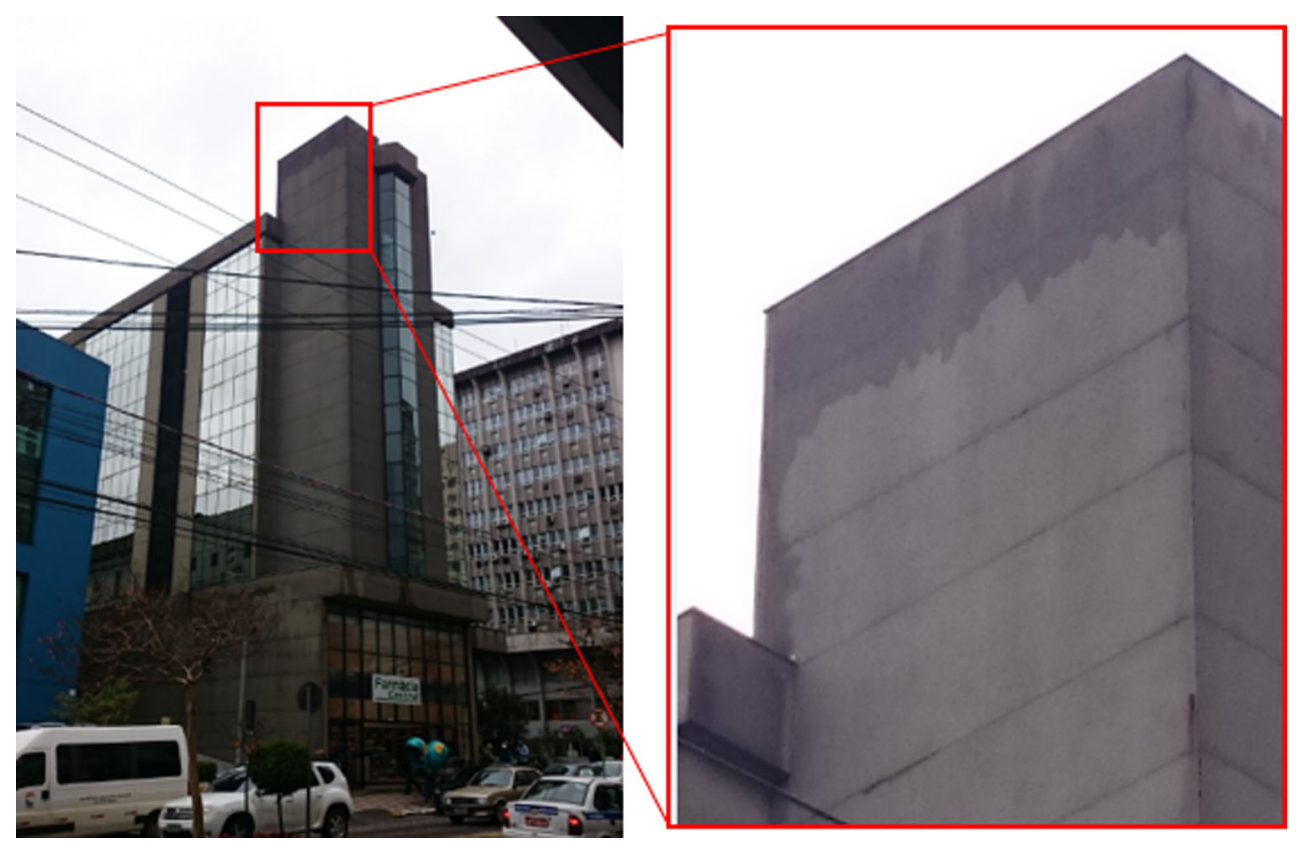

Fig. 3 Wetting geometry identified on the field

region. Orientations North (N), Northeast (NE), East (E), Southeast (SE), South (S), Southwest (SW), West (W) and Northwest (NW) were studied. In addition, as the case study consider just facades, the inclination adopted was $90^{\circ}$, which results in a $R_{1}$ coefficient of zero, as described in the Sect. 3.1.

In Brasilia, the urban plan of the city has one of the axes called by Monumental Axis, which is divided between North and South Wings (Fig. 4a). Along these wings are arranged three floors buildings in 400's blocks (Fig. 4b) and six floors residential buildings distributed in 100's, 200's and 300's blocks (Fig. 4c) The characteristics of buildings found in the town make these types considered as representative for the case study.

As the urban plan just allows buildings up to six floors, it was considered the height between 10 and $20 \mathrm{~m}$ as a representative of study area. This variable is important for the definition of $\mathrm{R}_{2}$ coefficient (0.1).

After the characterization of variables in question, the simulation was done, and the results are arranged in the form of Excel spreadsheet to be interpreted and discussed through tables and graphs.

\section{Results and discussion}

The results obtained from simulation are disposed on Table 1, representing the WDR monthly incidence quantified in each facade disposed to all orientations studied.

In June, there is no WDR for none of studied orientations, and this month is part of a period that can be called as dry (less or no rain) that occurs between April and September. The other period called as wet occurs between October and March, the months of November and December had the highest WDR values, especially for facades NW, N, W and NE.

In Fig. 5 the values of WDR are in ascending order, and quantified separately by wet and dry periods. There is a huge difference between these, in the former (wet period), the critical months are $\mathrm{N}$ and NW that received 125.21 and $120.40 \mathrm{~mm}$; respectively. On the other hand, SW and S orientations are the less influenced, receiving 36.58 and $36.15 \mathrm{~mm}$. Wet period represented an incidence of $75 \%$ of the WDR of all orientations considered, and the latter (dry period) has much less incidence of WDR. The most critical orientations on dry period are SE $(42.60 \mathrm{~mm})$ and $\mathrm{S}$ $(38.64 \mathrm{~mm})$, moreover, $\mathrm{W}$ had the lowest occurrence $(10 \mathrm{~mm})$, representing a value of 12.5 times lower than $\mathrm{N}$ facade in wet period (highest incidence).

With the annual sum shown in Table 1 and the graphic representation of Fig. 5 is possible to identify the facades that received more incidence of WDR. In percentage, classification in the following order is: $\mathrm{N}(18 \%)$, NW (17\%), NE (14\%), E (12\%), W (12\%), SE (11\%), S $(10 \%)$ and SW (7\%).

The incidence of WDR may cause higher degradation levels on the facades disposed in the orientations with more incidence of this variable. As mentioned on Sect. 1, problems related with infiltration, efflorescence, staining and detachments on facades are related to moisture. It can be confirmed in the results of Silva [26] and Souza [27] for Brasília case that found the overall order of degradation according to facades orientations: N, W, E and S. These 

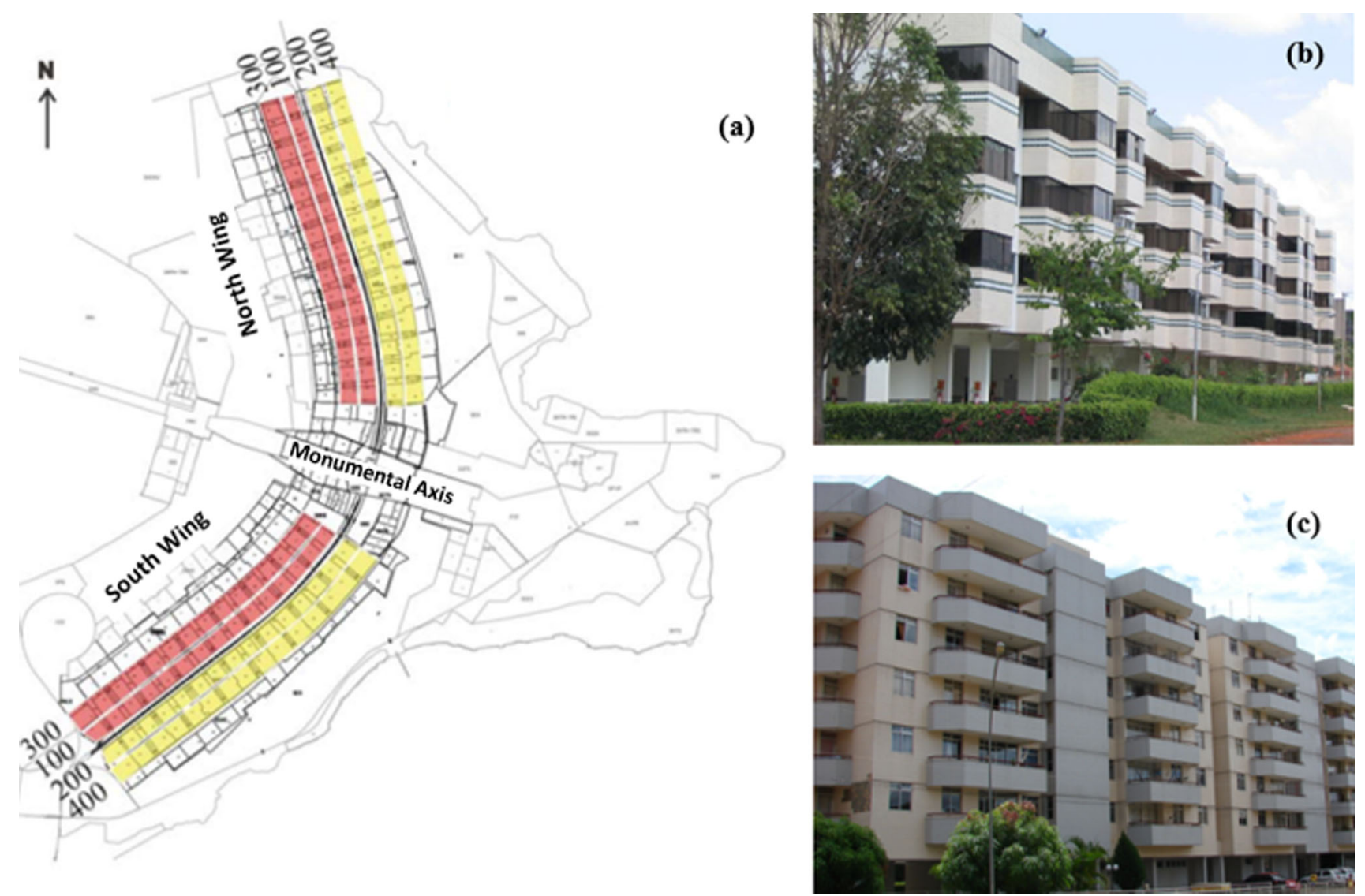

Fig. 4 a Brasilia's map, b typical building of 400's blocks and c typical building of 100's, 200's and 300's blocks, adapted from Amorim and Flores [25] and Silva [26]

Table 1 WDR obtained by WUFI ${ }^{\circledR}$ method in each orientation $(\mathrm{mm} / \mathrm{month})$

\begin{tabular}{lllllllll}
\hline Months & $\mathrm{N}$ & $\mathrm{NE}$ & $\mathrm{E}$ & $\mathrm{SE}$ & $\mathrm{S}$ & $\mathrm{SW}$ & $\mathrm{W}$ & $\mathrm{NW}$ \\
\hline January & 9.31 & 4.99 & 3.07 & 1.78 & 2.28 & 3.67 & 8.23 & 10.40 \\
February & 12.59 & 9.64 & 5.41 & 4.95 & 6.71 & 9.81 & 11.54 & 13.44 \\
March & 26.23 & 23.94 & 13.44 & 5.37 & 3.77 & 3.98 & 7.67 & 17.18 \\
April & 15.20 & 15.75 & 12.67 & 9.21 & 7.98 & 5.61 & 5.56 & 9.29 \\
May & 0.58 & 0.60 & 1.64 & 5.21 & 6.67 & 4.30 & 0.78 & 0.29 \\
June & - & - & - & - & - & - & - & - \\
July & - & - & 4.17 & 6.11 & 4.47 & 0.21 & - & - \\
August & 0.81 & 6.01 & 13.38 & 15.47 & 9.28 & 2.77 & 0.32 & 0.25 \\
September & 1.22 & 1.12 & 2.10 & 6.60 & 10.24 & 8.38 & 3.34 & 1.11 \\
October & 13.71 & 9.68 & 18.07 & 20.85 & 15.50 & 4.10 & 8.40 & 12.75 \\
November & 34.64 & 17.63 & 6.42 & 2.94 & 5.19 & 11.90 & 27.77 & 38.86 \\
December & 28.73 & 17.83 & 11.03 & 5.66 & 2.70 & 3.12 & 16.26 & 27.77 \\
Annual (mm/year) & 143.02 & 107.19 & 91.40 & 84.15 & 74.79 & 57.85 & 89.87 & 131.34 \\
\hline
\end{tabular}

authors identified on ceramic tile claddings higher occurrence of detachment, cracking, efflorescence and fail of joints in the $\mathrm{N}$ orientation, which is the main incidence of WDR. Obviously, radiation also influences the natural degradation process, but WDR plays an important role due to the fact that this agent is the main source of moisture in the facades.
According to results N, NW and NE facades orientations may have a tendency to possess the worst conditions of degradation, due to the presence of moisture associated with WDR. The results presented by WUFI $^{\circledR}$ can be a useful tool on design process and during the service life of building, mainly to establish definitions of priorities of preventive maintenance plans. These strategies allow a 
Fig. 5 Distribution of WDR incidence in each orientation (mm/month)

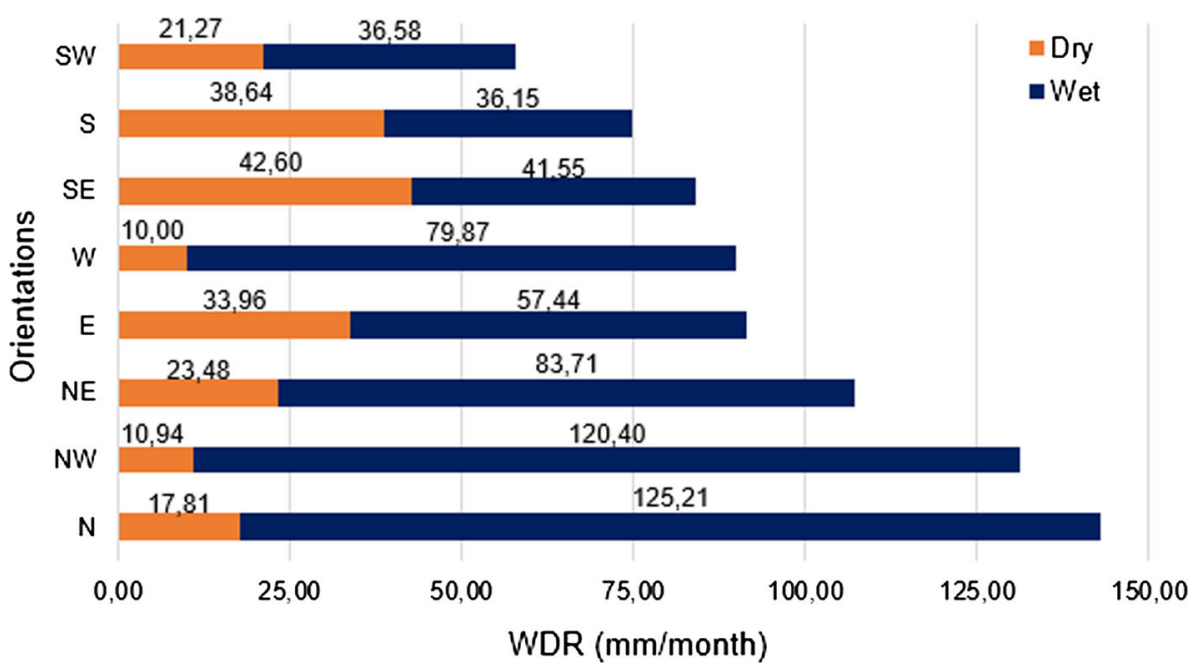

reduction in repair costs, and influence on increasing of service life of facades by means of appropriate performance conditions.

\section{Conclusions}

This paper aims to apply the hygrothermal simulation on quantification of WDR focusing on buildings' degradation. A study on quantification of WDR was presented to the city of Brasília-Brazil, using the method proposed by WUFI ${ }^{\circledR}$ Pro 5.3 software. Thus, it was possible to obtain the following conclusions.

The most critical orientations for WDR incidence to the case of Brasília were $\mathrm{N}, \mathrm{NW}$ and NE, with the percentage of incidence of 18, 17 and $14 \%$; respectively. These orientations may have the tendency to present anomalies related to moisture and the worst conditions of degradation as confirmed in previous studies. The other orientations had the occurrence: E (12\%), W (12\%) SE (11\%), S (10\%) and $\mathrm{SW}(7 \%)$.

Values obtained can be used as design parameters in order to assist designers regarding the most critical guidelines and allow decisions to be taken in these orientations. As well as to associate the critical orientations with facades' degradation degree. Moreover, as an auxiliary tool in the diagnosis of anomalies, as well as degradation quantification methods and defining maintenance aspects. Then, it is suggested to use the hygrothermal simulation software as tool for quantification of climatic agents, and later facades degradation comparison.

Finally, these results showed the importance of WUFI ${ }^{\circledR}$ method, as well as the rain WDR quantification methods. The WUFI ${ }^{\circledR}$ proved to be an easy useful tool and able to quantify the WDR, without hiding seasonal weather effects. The wet period was the most responsible for incidence of WDR, representing $75 \%$. Moreover, the software has several other features related to the hygrothermal performance of materials to be studied. Faced with this, it is suggested the comparison of other methods considering several world cities, in order to check what the best one, for WDR accounting according to orientations of facades.

Acknowledgments The authors would like to thank the University of Brasília (UnB), the Postgraduate Program in Structural Engineering and Construction (PECC), as well as Materials Testing Laboratory (LEM), and National Council for Scientific and Technological Development (CNPq).

\section{References}

1. Straube JF (2002) Moisture in buildings. ASHRAE J 44:15-19

2. Ramos NMM, Delgado JMPQ, Barreira E, de Freitas VP (2010) Hygrothermal numerical simulation: application in moisture damage prevention. In: Angermann L (ed) Numerical simulations-examples and applications in computational fluid dynamics, 1st edn. Intech, Chennai, pp 97-122

3. de Freitas VP, Corvacho H, Quintela M, Delgado JMPQ (2013) Durability assessment of adhesive systems for bonding ceramic tiles on facades: the research and the practice. In: de Freitas VP, Delgado JMPQ (eds) Durability of buildings materials and components, 1st edn. Springer, Berlin, pp 173-206

4. Blocken B, Carmeliet J (2010) Overview of three state-of-the-art wind-driven rain assessment models and comparison based on model theory. Build Environ 45:691-703

5. Giarma C, Aravantinos D (2011) Estimation of building components' exposure to moisture in Greece based on wind, rainfall and other climatic data. J Wind Eng Ind Aerod 99:91-102

6. Bauer E, de Freitas VP, Mustelier N, Barreira E, de Freitas SS (2015) Infrared thermography-evaluation of the results reproducibility. Struct Surv 31(3):181-193

7. Bauer E, Pavón E, Barreira E, de Castro EK (2016) Analysis of building facade defects using infrared thermography: laboratory studies. J Build Eng 6:93-104

8. Wetzel A, Herwegh M, Zurbriggen R, Winnefeld F (2012) Influence of shrinkage and water transport mechanisms on 
microstructure and crack formation of tile adhesive mortars. Cement Concrete Res 42:39-50

9. Zurbriggen R, Herwegh M (2016) Daily and seasonal thermal stresses in tilings: a field survey combined with numeric modeling. Mater Struct 49(5):1917-1933

10. Sulaiman H, Olsina F (2014) Comfort reliability evaluation of building designs by 19 stochastic hygrothermal simulation. Renew Sustain Energy Rev 40(20):171-184

11. Straube J (2016) BSD-148: simplified prediction of driving rain on buildings: ASHRAE 160P and WUFI 4.0. Build Sci Corp. http://www.buildingscience.com/documents/digests/bsd-148-wufisimplified-driving-rain-predictionofsubordinatedocument. Accessed 27 Jan 2016

12. Blocken B, Carmeliet $\mathrm{J}$ (2004) A review of wind-driven rain research in building science. $\mathrm{J}$ Wind Eng Ind Aerod 92(13):1079-1130

13. Van mook FJ (1999) Full-scale measurements and numeric simulations of driving rain on a building. In: Proceedings of 10th international conference on wind engineering, Copenhagen, pp 1145-1152

14. Ge H, Krpan R (2007) Field measurement of wind-driven rain on a low-rise building in the coastal climate of British Columbia. In: Proceedings of 11th Canadian conference on building science and technology, Banff

15. Kubilay A, Derome D, Blocken B, Carmeliet J (2014) Highresolution field measurements of wind driven rain on an array of low-rise cubic buildings. Build Environ 78:1-13

16. Blocken B, Abuku M, Nore K, Briggen PM, Schellen HL, Thue JM, Roels S, Carmeliet J (2011) Intercomparison of wind-driven rain deposition models based on two case studies with full-scale measurements. J. Wind Eng Ind Aerod 99:448-459

17. Straube JF, Burnett EFP (2000) Simplified prediction of driving rain on buildings. In: Proceedings of the international building physics conference, Eindhoven, pp 375-382

18. Kubilay A, Derome D, Blocken B, Carmeliet J (2015) Numerical modeling of turbulent dispersion for wind-driven rain on building facades. Environ Fluid Mech 15:109-133
19. Freitas ASSLA (2011) Hygrothermal behavior assessment of facades exterior coatings due to the action of wind-driven rain. Master Thesis, FEUP, Porto (In Portuguese)

20. Karagiozis A, Hadjisophocleous G, Cao S (1997) Wind-driven rain distributions on two buildings. J Wind Eng Ind Aerod 67-68:559-572

21. WUFI Pro 5.3 (2013) IBP—Fraunhofer Institute for Building Physics. Holzkirchen, Germany

22. Straube JF (1998) Moisture control and enclosure wall systems. $\mathrm{PhD}$ Thesis, University of Waterloo, Ontario

23. Vallejo FJL (1990) Ensuciamiento de fachadas pétreas por la contaminación atmosférica. El caso de la ciudad de Valladolid: Universidad, España. Informes de la Construcción, Madrid, Instituto Eduardo Torroja 41(405):45-72

24. Roriz M (2012) Corrections to irradiance and illuminances of EPW files ANTAC base. Working Group on Comfort and Energy Efficiency of Buildings-National Association of Technology of the Built Environment (ANTAC). http://www.labeee.ufsc.br/ downloads/arquivosclimaticos/formato-epwofsubordinatedocument. Accessed 20 Jan 2016 (In Portuguese)

25. Amorim CA, Flores AL (2005) Residential buildings of superblocks of the Pilot Plan, Brasilia: preservation aspects and environmental comfort. In: Proocedings of "Encontro Nacional sobre conforto no ambiente Construído, e Conferência Latino-americana sobre conforto e desempenho energético de edificações". Maceió, Brazil, pp 37-46 (In Portuguese)

26. Silva MNB (2014) Quantitative evaluation of degradation and service life of facade's coatings - application to case of Brasilia/ Brazil. PhD Thesis, University of Brasília, Brasília, Brazil (In portuguese)

27. Souza JS (2016) Evolution of facades degradation-effect of degradation agents and constituent elements. Master Thesis, University of Brasília, Brasília, Brazil (In Portuguese) 